\title{
Differential diagnosis and clinical decision-making in physical therapy: Case report of a complex dizzy patient
}

\author{
Eric G. Johnson ${ }^{1 *}$, Chethan Akkur Channe Gowda ${ }^{2}$ and Ahmad A. Alharbi ${ }^{2}$
}

*Correspondence: ejohnson@llu.edu

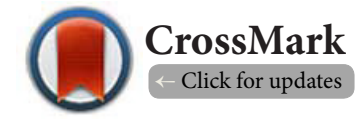

1Professor, Loma Linda University, Department of Physical Therapy, Loma Linda, CA, USA.

${ }^{2}$ Graduate Student, Loma Linda University, Department of Physical Therapy, Loma Linda, CA, USA.

\begin{abstract}
Background: This case report describes the physical therapy differential diagnostic and clinical decisionmaking processes utilized in the management of a complex dizzy patient.

Case presentation: A 55 year-old female patient with a congenital eye defect was initially diagnosed with left horizontal cupulolithiasis that was converted to horizontal canalithiasis using a modified liberatory maneuver. After resolving the left horizontal canalithiasis, the patient was diagnosed with left unilateral vestibular hypofunction, which was successfully treated by the physical therapist.

Discussion: Over a period of 23 days and 5 physical therapy sessions, the patient management approach included examination (subjective and physical), evaluation of findings, physical therapy diagnosis, prognosis, plan of care, intervention, and evaluation of outcomes.

Conclusion: This case report demonstrates the need for physical therapists to incorporate a comprehensive patient management approach in order to efficiently maximize patient outcomes.
\end{abstract}

Keywords: Physical therapy, vestibular rehabilitation, clinical decision-making

\section{Background}

The American Physical Therapy Association (APTA) describes physical therapy diagnosis as a process used to label and identify the impact that a condition has on function [1]. The physical therapy diagnostic process is driven by clinical decision-making (CDM) including physical therapy scope of practice considerations. There are several CDM models including the APTA patient management CDM model, the hypothesis-oriented algorithm for clinicians (HOAC II), and neurologic patient-specific frameworks described by Sullivan et al., and Schenkman et al., [1-4]. While each CDM model has its unique aspects, there is considerable overlap. In this case report, we utilized the APTA patient management CDM model [1].

The APTA patient management CDM model includes examination (subjective and physical), evaluation, physical therapy diagnosis, prognosis, plan of care, intervention, and evaluation of outcomes [1]. The subjective examination includes a detailed patient history and pertinent questions intended to facilitate a physical therapy diagnostic hypothesis. Subsequently, specific physical examinations are performed and evaluated to support or refute the physical therapy diagnostic hypothesis. Periodically, clinicians determine that a patient is not appropriate for physical therapy and further medical consultation is warranted [2]. Otherwise, the clinician reaches a physical therapy diagnosis, determines prognosis, and generates a plan of care. The intervention is implemented and outcome measures are obtained during each session. The plan of care for dizzy patients often includes vestibular rehabilitation therapy (VRT) $[5,6]$.

Patients with dizziness can be challenging for physical therapists to manage because of the inherent complexity of the condition. Many dizzy patients are referred to physical therapy with non-specific diagnoses and the responsibility is placed on the physical therapist to determine the origin of symptoms in order to decide the appropriate plan of care. Therefore, the purpose of this case report was to describe the CDM process utilized during the management of a complex dizzy patient. The patient was selected because of the non-specific medical diagnosis provided by the physician as well as the need for continual re-examination and physical therapy differential diagnosis throughout the patient management process. 


\section{Case presentation}

\section{Subjective examination}

The patient was a 55 year-old female nurse who experienced sudden insidious onset of nausea, emesis and vertigo upon waking in the morning. A family member drove her to the emergency department (ED) where an ED physician made a medical diagnosis of benign paroxysmal positional vertigo (BPPV). The type of BPPV (canalithiasis or cupulolithiasis), specific semicircular canal (anterior, posterior, horizontal), and involved side (right or left) were not determined. The patient was discharged with a prescription of Meclizine to be taken as needed and to follow-up with her primary care physician. The patient's brother was a physical therapist and he contacted the primary author requesting a physical therapy consultation for vestibular rehabilitation.

The physical therapy consultation occurred 3 days after the initial onset of symptoms. The patient was unable to drive because of her symptoms so a family member drove her to the appointment. The patient's chief complaints included vertigo, unsteady gait, nausea, and emesis exacerbated by quick movements. Past medical history was unremarkable and current symptoms ranged from 8-10/10, as per the visual analog scale (VAS), and her current VAS was $8 / 10$. The patient was taking Meclizine several times daily for nausea and emesis. No co-morbidities were reported. After concluding the subjective history, the physical therapy diagnostic hypothesis supported the physician's medical diagnosis of BPPV. The patient goals included resolving her dizziness and nausea so she could resume driving and return to work. A general description of VRT examinations and interventions utilized in the present case report is provided in Tables 1 and 2 .

\section{Physical examination}

The results of cervical spine vascular system and central nervous system medical screening examinations (clonus, Babinski sign, deep tendon reflexes, dysdiadochokinesia, finger-to-nose eyes open and closed, and heel-to-shin eyes open and closed) were unremarkable. Additionally, a mild first-degree gaze-

Table 1. General Description of Vestibular-Related Physical Examinations Utilized in Case Report.

\begin{tabular}{|c|c|}
\hline Dix-Hallpike Test & $\begin{array}{l}\text { Purpose: examines for benign paroxysmal positional vertigo (BPPV) in the vertical semicircular canals (SCC's) } \\
\text { Procedure: patient assisted into supine position with neck rotated 30-45 degrees and head slightly below } \\
\text { the horizontal plane; position maintained for } 60 \text { seconds; clinician observes for nystagmus and symptom } \\
\text { provocation } \\
\text { Sensitivity and Specificity: } 79 \% \text { and } 75 \% \text {, respectively [7] }\end{array}$ \\
\hline Roll Test & $\begin{array}{l}\text { Purpose: examines for BPPV in the horizontal SCC's } \\
\text { Procedure: patient begins in supine position with neck flexed } 30 \text { degrees; patient's head rotated } 30-45 \text { degrees } \\
\text { to each side; each position maintained for } 60 \text { seconds; clinician observes for nystagmus and symptom } \\
\text { provocation } \\
\text { Sensitivity and Specificity: Not established }\end{array}$ \\
\hline Head Impulse Test & $\begin{array}{l}\text { Purpose: examines for vestibular hypofunction } \\
\text { Procedure: patient seated with head flexed } 30 \text { degrees and asked to focus on clinician's chin; clinician performs } \\
\text { head thrusts toward each side and observes for corrective saccades } \\
\text { Sensitivity and Specificity: } 71 \%-84 \% \text { and } 82 \% \text {, respectively [8] }\end{array}$ \\
\hline $\begin{array}{l}\text { Head Shaking-Induced } \\
\text { Nystagmus Test }\end{array}$ & $\begin{array}{l}\text { Purpose: examines for vestibular hypofunction } \\
\text { Procedure: patient seated with head flexed } 30 \text { degrees and asked to focus on clinician's chin then asked to close } \\
\text { eyes; clinician performs passive head rotations to each side for approximately } 10 \text { seconds; patient opens their } \\
\text { eyes and clinician observes for nystagmus } \\
\text { Sensitivity and Specificity: } 27 \% \text { and } 85 \% \text {, respectively [9] }\end{array}$ \\
\hline
\end{tabular}

Table 2. General Description of Vestibular-Related Interventions Utilized in Case Report.

\begin{tabular}{ll}
$\begin{array}{l}\text { Modified Brandt-Daroff } \\
\text { Maneuver }\end{array}$ & $\begin{array}{l}\text { Patient instructed to flex head slightly downward then lie down on one side maintaining head position; } \\
\text { position maintained for } 60 \text { seconds; patient then returns to upright sitting for } 60 \text { seconds; patient then lies } \\
\text { down on other side maintaining head position; position maintained for } 60 \text { seconds before returning to } \\
\text { upright sitting }\end{array}$ \\
$\begin{array}{ll}\text { Horizontal Canalith } \\
\text { Repositioning Maneuver }\end{array}$ & $\begin{array}{l}\text { Intervention begins with patient supine and neck flexed } 30 \text { degrees; clinician rotates patients head } 30-45 \\
\text { degrees to involved side; rotates head back to neutral; rotates head to uninvolved side; patient assisted into } \\
\text { prone position turning body towards uninvolved side without head rotation; patient assisted into supine } \\
\text { turning body towards involved side with head rotated } 30-45 \text { degrees towards involved side; each position is } \\
\text { maintained for } 60 \text { seconds and neck flexed } 30 \text { degrees throughout }\end{array}$ \\
\hline $\begin{array}{l}\text { Gaze Stability } \\
\text { X1 Exercises }\end{array}$ & $\begin{array}{l}\text { Patient actively rotates their head from side to side while looking at a stationary target for } 15-30 \text { seconds at a } \\
\text { speed that slightly increases their symptoms; intervention systematically progressed as tolerated }\end{array}$ \\
$\begin{array}{l}\text { Gaze Stability } \\
\text { X2 Exercises }\end{array}$ & $\begin{array}{l}\text { Patient actively rotates their head from side to side while looking at a moving hand held target for } 15-30 \\
\text { seconds at a speed that slightly increases their symptoms; the head and target move in opposite directions; } \\
\text { intervention systematically progressed as tolerated }\end{array}$
\end{tabular}




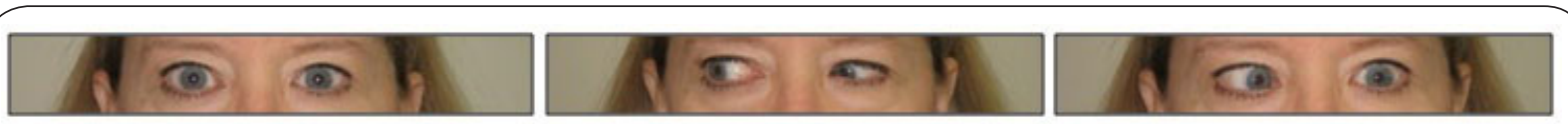

Figure 1. Left Eye Lateral Gaze Congenital Defect.

evoked nystagmus was observed when the patient looked to her right; which could suggest a left unilateral vestibular hypofunction given that all other CNS screening tests were normal. Also, an abnormal smooth pursuit test with inability to abduct left eye past midline was observed. The patient stated that this was a congenital defect (Figure 1).

Given the physical therapy diagnostic hypothesis of BPPV, the clinician decided to use the Dix-Hallpike test to examine the vertical semicircular canals as the posterior semicircular canal is most commonly involved. The right Dix-Hallpike test was performed and judged as normal. The left Dix-Hallpike test was performed next and mild atypical horizontal nystagmus was observed but the patient's VAS only increased from 8/10 to $8.5 / 10$ and was judged as inconclusive $[7,10-13]$. Given the lack of evidence from the Dix-Hallpike test, the decision was made to use the Roll test to examine the less commonly af fected horizontal semicircular canals. The right Roll test was judged as inconclusive as eye movements were not clearly defined; however, symptoms were markedly produced and her VAS increased to 9.5/10. After a brief recovery time, the patient's VAS decreased to 8.5/10. Despite the high VAS scores, the patient requested that the examination continue. The left Roll test produced apogeotropic nystagmus that persisted beyond 60 seconds and the patient's VAS increased to $9 / 10$ and was judged as positive [14-16]. Because the left Roll test produced weaker symptoms, a physical therapy diagnosis of left horizontal cupulolithiasis BPPV was made. This physical therapy diagnosis was based on Ewald's second law, which states that horizontal cupulolithiasis is identified as the side of the Roll test that provokes the weaker apogeoptropic nystagmus [10-16]. The prognosis was favorable given the effective outcome physical therapy often has on BPPV and an estimated 3-4 physical therapy sessions were likely needed to improve the condition $[5-7,10]$. Following the clinical practice guidelines for BPPV, the plan of care was to treat the left horizontal SCC cupulolithiasis BPPV with the liberatory maneuver [10].

\section{Intervention}

The patient was seen for a total of 5 sessions over a period of 23 days.

\section{Session 1-(Day 1)}

After the physical therapy diagnosis of left horizontal cupulolithiasis was made, an active-assistive Brandt-Daroff maneuver was performed as a modified liberatory maneuver. Although the Casani or Gufoni maneuver is typically used for treating horizontal cupulolithiasis, it was not performed given its high velocity components and the irritability of the patient [10]. In other words, this decision was made because the patient's VAS was $9 / 10$ during the examinations and the Casani maneuver could push the VAS to 10/10, inducing emesis. Based on this concern, the patient was instructed to perform 3-5 repetitions of the Brandt-Daroff maneuver at a tolerable speed, 3 times daily as able, and to walk as much as possible daily.

\section{Session 2-(Day 2)}

The subjective symptoms improved to a VAS range of 6.5$8 / 10$ and she had not required Meclizine since the day prior as her nausea was much less. She was able to perform the Brandt-Daroff maneuver as prescribed and walked quite a bit throughout the day. Her chief complaint at this time was difficulty with visual clarity during head movements and vertigo to a lesser degree. The physical re-examination included the left Roll test. It was judged as positive with brief horizontal nystagmus of unclear directionality that fatigued in less than 30 seconds. Given the observed change with the left Roll test, otoconia was likely dislodged from the cupula as a result of the Brandt-Daroff maneuver and was now free floating in the horizontal SCC. A new physical therapy diagnosis of left horizontal canalithiasis was made. Following the clinical practice guidelines for BPPV, the intervention consisted of 4 left horizontal canalith repositioning maneuvers (CRM) performed over a period of fifteen minutes [10]. Nystagmus was no longer observed after the fourth horizontal CRM. The patient was then instructed in home performance of the horizontal CRM's to be done 3 times daily until the next session and to continue walking as much as able.

\section{Telephone Consultation-(3 days after initial consultation)} The patient was contacted by telephone the following day and she reported that vertigo and nausea were better and that the home program was going well.

\section{Session 3-(4 days after initial consultation)}

The patient reported symptoms had improved to a VAS range of 3-6/10 and she had not taken Meclizine since the day of the initial physical therapy consultation. Her chief complaint at this time remained difficulty with visual clarity during head movements and she no longer reported vertigo. The physical re-examination began with the left Roll test and it was judged as normal. A head impulse test was then performed and judged as positive to the left. A head shaking-induced nystagmus test using infrared goggles was performed next and judged as positive with approximately 10 beats of nystagmus to the right [17-20]. It was determined that the BPPV was resolved and a new physical therapy diagnosis of Left Unilateral Vestibular Hypofunction (L-UVH) was made. Although 
unilateral vestibular hypofunctions can take several months to resolve, the prognosis was again favorable and an estimated 3-4 physical therapy sessions were likely needed to improve the condition [20]. Following the clinical practice guidelines for vestibular hypofunctions, the new plan of care and home program included 3 sets of Gaze Stability X1 Exercises, each set performed for 30 seconds as tolerated and to continue walking as much as able [20].

\section{Session 4-(8 days after initial consultation)}

The patient reported symptoms had improved to a VAS range of 2-6/10 and home program was going well. Her chief complaint at this time remained difficulty with visual clarity during head movements. The physical re-examination of the head impulse test and the head shaking-induced nystagmus test both remained positive. The intervention consisted of home program progression. The patient was instructed to perform 3 sets of seated Gaze Stability X2 Exercises, each set performed for 30 seconds. During Gaze Stability X2 Exercises, the patient's head and target move in opposite directionswhile maintaining focus on the target. Next, the patient was instructed to perform Gaze Stability X1 Exercises with walking forward and backward approximately 10 feet. She performed 3 sets, each set performed for 30 seconds. The patient tolerated this well. Her home program was modified to include 3 sets of 5 BrandtDaroff exercises/maneuvers 3 times daily; Gaze Stability X1 Exercises 3 times daily; Gaze Stability X2 Exercises 1-3 times daily to include sitting in the driver's seat of a parked car (to simulate her commute) as well as in walking forward and backward as able. She was scheduled to see her primary care physician 4 days later. A progress report was sent by e-mail to the patient prior to her physician visit. Communication via e-mail was planned for after the physician visit.

\section{E-Mail Consultation-(14 days after initial consultation)}

The patient's physician visit "Went well and she was appreciative of your report". The patient reported that she was $75-80 \%$ recovered and her physician recommended she continue with physical therapy.

\section{Session 5-(23 days after initial consultation)}

The patient reported symptoms were negligible and rated them as a VAS range of $0-1 / 10$. She said she had been driving for several days. The only reported complaints at this time were unsteadiness with quick total body movements to her left and difficulty focusing on cars greater than 7-8 vehicles ahead. The physical re-examination of the head impulse test remained positive; however, the head shaking-induced nystagmus test was negative. The home program was modified to include Gaze Stability X1 Exercises with visually complex background at an estimated distance of 7-8 vehicles, 3 repetitions of 30 seconds each in vertical and horizontal planes 2 times daily; Gaze Stability X2 Exercises with visually complex background 3 repetitions of 30 seconds each in vertical and horizontal planes 2 times daily; motion sensitivity exercise (similar to provoking activity) 5 repetitions 2 times daily; and daily walking as much as able. The patient was discharged at this time and an e-mail follow-up was scheduled to ensure that continued progress was occurring.

\section{E-Mail Consultation-(49 days after initial consultation)}

The patient reported she had been driving without dizziness and stated that "The problem with focusing down the road while driving is almost resolved, so I'm basically good as new." The patient also reported that she had successfully returned to work a couple of weeks prior.

\section{Discussion}

This case report describes the physical therapy differential diagnosis and clinical decision-making process with a complex dizzy patient. Physical therapy diagnosis is a process used to label and identify the impact that a condition has on function [1]. However; in some cases, physical therapy diagnosis includes the pursuit of pathological origin. For example, many patients are referred to physical therapy with a medical diagnosis of "dizziness", which is a symptom rather than pathology. In order to provide the appropriate clinical intervention, physical therapy examination and evaluation are performed to determine the origin of the dizziness. In the present case, successful and efficient management of BPPV was dependent upon knowing the specific type of BPPV, which semicircular canal was affected, and the side of involvement. Using the Dix-Hallpike test, the clinician was able to make a physical therapy differential diagnosis and develop the appropriate plan of care. Additionally, re-examination was important as the primary diagnosis changed over the course of physical therapy management and new physical therapy diagnoses were made.

The physical therapy diagnostic process is driven by CDM and requires determination of whether or not a patient's clinical presentation is within the scope of physical therapy practice. Fortunately, several physical therapy CDM models exist and they greatly facilitate improved patient management [1-4]. Schenkman et al., [4] report that CDM frameworks are "instrumental in guiding clinicians through a comprehensive process of patient management, communicating with other healthcare providers and facilitating the educational process." We wholeheartedly agree with this statement.

In 1989, Echternach and Rothstein published the first CDM framework (HOAC) and subsequently updated it (HOAC II) in 2003 [3,21]. These pioneering CDM frameworks have served the physical therapy profession very well by facilitating a sense of cognitive efficiency relating to patient management. Other CDM frameworks have since emerged that provide additional resources to the HOAC II. Sullivan et al., [2] reported that the HOAC II "does not direct the physical therapist in the differential diagnosis process." In 2004, they published a CDM framework focusing on determining appropriateness 
of physical therapy for patients with neurologic disorders. This is particularly relevant as the physical therapy profession moves towards direct access. Boissonnault and Ross [22] identified 78 published case reports where physical therapists referred patients to physicians and subsequent medical diagnoses were made. The authors stated that "an important role for physical therapists in the healthcare delivery system is to recognize when patient referral to a physician or other healthcare provider is indicated." Schenkman et al., [4] identified a need to improve the "patient-centeredness" of CDM frameworks by incorporating patient enablement and disablement models. Their framework is intended to guide comprehensive physical therapy practice as well as provide a platform for educating future clinicians. The APTA patient management CDM framework is flexible enough in its format that clinicians can incorporate aspects of multiple CDM models on a case-by-case basis [1].

\section{Conclusion}

This case report illustrates the physical therapy differential diagnosis and clinical decision-making processes used with a complex dizzy patient. The subjective examination was used to generate a diagnostic hypothesis and specific physical examinations were performed and evaluated to support it. Once the physical therapy diagnosis was made, prognosis and plan of care were determined. Appropriate interventions were implemented and the patient was re-examined each session. This comprehensive physical therapy patient management approach led to an efficient and positive treatment outcome.

\section{List of abbreviations}

APTA: The American Physical Therapy Association

CDM: Clinical decision-making

HOAC: The hypothesis-oriented algorithm for clinicians

VRT: Vestibular rehabilitation therapy

ED: Emergency department

BPPV: Benign paroxysmal positional vertigo

SSC's: Semicircular canals

VAS: Visual analog scale

L-UVH: Left unilateral vestibular hypofunction

\section{Competing interests}

The authors declare that they have no competing interests.

\section{Authors' contributions}

\begin{tabular}{|l|c|c|c|}
\hline Authors' contributions & EGJ & CACG & AAA \\
\hline Research concept and design & $\checkmark$ & -- & -- \\
\hline Collection and/or assembly of data & $\checkmark$ & $\checkmark$ & -- \\
\hline Data analysis and interpretation & $\checkmark$ & -- & -- \\
\hline Writing the article & $\checkmark$ & -- & -- \\
\hline Critical revision of the article & $\checkmark$ & $\checkmark$ & $\checkmark$ \\
\hline Final approval of article & $\checkmark$ & $\checkmark$ & $\checkmark$ \\
\hline Statistical analysis & $\checkmark$ & $\checkmark$ & $\checkmark$ \\
\hline
\end{tabular}

Acknowledgement

The author's thank the Loma Linda University Department of Physical Therapy for supporting this effort.
Publication history

Editor: Gordon John Alderink, Grand Valley State University, USA. Received: 16-Mar-2017 Final Revised: 23-Apr-2017

Accepted: 01-May-2017 Published: 21-May-2017

\section{References}

1. Guide to Physical Therapist Practice. Second Edition. American Physical Therapy Association. Phys Ther. 2001; 81:9-746. | PubMed

2. Sullivan KL, Hershberg J, Howard R and Fisher BE. Neurologic differential diagnosis for physical therapy. Journal of Neurologic Physical Therapy. 2004; 28:162-168. | Article |

3. Rothstein JM, Echternach JL and Riddle DL. The Hypothesis-Oriented Algorithm for Clinicians II (HOAC II): a guide for patient management. Phys Ther. 2003; 83:455-70. | Article | PubMed

4. Schenkman M, Deutsch JE and Gill-Body KM. An integrated framework for decision making in neurologic physical therapist practice. Phys Ther. 2006; 86:1681-702. | Article | PubMed

5. Vestibular Disorders Association. | Website

6. Herdman SJ and Clendaniel RA. Vestibular Rehabilitation, 4th Edition. F.A. Davis, Pennsylvania. 2014.

7. Halker RB, Barrs DM, Wellik KE, Wingerchuk DM and Demaerschalk $B M$. Establishing a diagnosis of benign paroxysmal positional vertigo through the dix-hallpike and side-lying maneuvers: a critically appraised topic. Neurologist. 2008; 14:201-4. | Article | PubMed

8. Schubert MC, Tusa RJ, Grine LE and Herdman SJ. Optimizing the sensitivity of the head thrust test for identifying vestibular hypofunction. Phys Ther. 2004; 84:151-8. | Article | PubMed

9. Jacobson GP, Newman CW and Safadi I. Sensitivity and specificity of the head-shaking test for detecting vestibular system abnormalities. Ann Otol Rhinol Laryngol. 1990; 99:539-42. | Article | PubMed

10. Bhattacharyya N, Gubbels SP, Schwartz SR, Edlow JA, El-Kashlan H, Fife $T$, Holmberg JM, Mahoney K, Hollingsworth DB, Roberts R, Seidman MD, Steiner RW, Do BT, Voelker CC, Waguespack RW and Corrigan MD. Clinical Practice Guideline: Benign Paroxysmal Positional Vertigo (Update). Otolaryngol Head Neck Surg. 2017; 156:S1-S47. | Article | PubMed

11. Steenerson RL, Cronin GW and Marbach PM. Effectiveness of treatment techniques in 923 cases of benign paroxysmal positional vertigo. Laryngoscope. 2005; 115:226-31. | Article | PubMed

12. $\mathrm{Han} \mathrm{BI}, \mathrm{Oh} \mathrm{HJ}$ and Kim JS. Nystagmus while recumbent in horizontal canal benign paroxysmal positional vertigo. Neurology. 2006; 66:706-10. | Article | PubMed

13. Hornibrook J. Benign Paroxysmal Positional Vertigo (BPPV): History, Pathophysiology, Office Treatment and Future Directions. Int J Otolaryngol. 2011; 2011:835671. | Article | PubMed Abstract | PubMed FullText

14. Nguyen-Huynh AT. Evidence-based practice: management of vertigo. Otolaryngol Clin North Am. 2012; 45:925-40. | Article I PubMed Abstract | PubMed FullText

15. Flock $A$ and Wersall J. A study of the orientation of the sensory hairs of the receptor cells in the lateral line organ of fish, with special reference to the function of the receptors. J Cell Biol. 1962; 15:19-27. | Article | PubMed Abstract | PubMed FullText

16. Nuti $D$, Vannucchi $P$ and Pagnini P. Benign paroxysmal positional vertigo of the horizontal canal: a form of canalolithiasis with variable clinical features. J Vestib Res. 1996; 6:173-84. | Article | PubMed

17. McIntyre AK. The quick component of nystagmus. J Physiol. 1939; 97:816 | Article | PubMed Abstract | PubMed FullText

18. Schubert MC and Minor LB. Vestibulo-ocular physiology underlying vestibular hypofunction. Phys Ther. 2004; 84:373-85. | Article I PubMed

19. Hain TC, Fetter $M$ and Zee DS. Head-shaking nystagmus in patients with unilateral peripheral vestibular lesions. Am J Otolaryngol. 1987; 8:36-47. | Article | PubMed

20. Hall CD, Herdman SJ, Whitney SL, Cass SP, Clendaniel RA, Fife TD, Furman 
Johnson et al. Physical Therapy and Rehabilitation 2017,

http://www.hoajonline.com/journals/pdf/2055-2386-4-2.pdf

JM, Getchius TS, Goebel JA, Shepard NT and Woodhouse SN. Vestibular Rehabilitation for Peripheral Vestibular Hypofunction: An EvidenceBased Clinical Practice Guideline: FROM THE AMERICAN PHYSICAL THERAPY ASSOCIATION NEUROLOGY SECTION. J Neurol Phys Ther. 2016; 40:124-55. | Article | PubMed Abstract | PubMed FullText

21. Echternach JL and Rothstein JM. Hypothesis-oriented algorithms. Phys Ther. 1989; 69:559-64. | Article | PubMed

22. Boissonnault WG and Ross MD. Physical therapists referring patients to physicians: a review of case reports and series. J Orthop Sports Phys Ther. 2012; 42:446-54. | Article | PubMed

\section{Citation:}

Johnson EG, Gowda CAC and Alharbi AA. Differential diagnosis and clinical decision-making in physical therapy: Case report of a complex dizzy patient. Phys Ther Rehabil. 2017; 4:2.

http://dx.doi.org/10.7243/2055-2386-4-2 